\title{
Neurological sequelae of COVID-19: a review
}

\author{
Christopher J. Peterson ${ }^{1}$, Ashish Sarangi ${ }^{2^{*}}$ (D) and Fariha Bangash ${ }^{3}$
}

\begin{abstract}
Background: The COVID-19 pandemic has produced a myriad of challenges, including identifying and treating neurological sequelae.

Main body: COVID-19 can cause olfactory and respiratory dysfunction with average recovery within 1 month and a minority of patients experiencing symptoms at 8-month follow-up. Headaches are also very common (up to 93\%) amongst patients with persistent COVID-19 symptoms. COVID-19 illness may also affect cognition, although results are mixed.

Conclusion: While many studies have focused on acute COVID-19 symptoms, more longitudinal studies will need to assess the neurological sequelae of the disease. Furthermore, care must be taken when attributing sequelae to COVID-19 illness and not an unrelated cause. Finally, there is concern that COVID-19 may be associated with secondary illnesses, such as Guillain-Barre, and may even contribute to the development of diseases, such as Alzheimer's.
\end{abstract}

Keywords: COVID-19, SARS-CoV-2, Neurological, Long term, Sequelae

\section{Background}

The coronavirus disease 2019 (COVID-19) pandemic has presented many challenges, not the least of which is understanding the sequelae effects of the disease. While the early phases of the pandemic understandably focused on the acute clinical presentation of illness, as infection rates begin to fall globally it will be crucial to understand the lasting effects of COVID-19 illness. Neurological sequelae are of special interest both because of their potential to be life-altering as well as the seemingly unexpected nature of these effects for a respiratory virus. While a tremendous effort has been undertaken to prevent and treat severe acute respiratory syndrome coronavirus 2 (SARS-CoV-2) infections, physicians will also be tasked with identifying and treating lingering effects of SARS-CoV-2 long after patients have cleared the virus.

Possible acute neurological consequences of COVID19 range from olfactory and gustatory dysfunction to encephalopathy and stroke [1]. Up to 90\% of COVID-19

\footnotetext{
*Correspondence: aks_sarangi@hotmail.com

${ }^{2}$ Department of Psychiatry, Texas Tech University Health Sciences Center, 3601 4th St., Lubbock, TX 79430, USA

Full list of author information is available at the end of the article
}

patients have reported to have at least one neurological symptom [2]. Even patients without observable neurological manifestations exhibited neurological microstructure changes at 3-month follow-up [3], suggesting that neurological effects could be much more widespread than anticipated.

The etiology for COVID-19 neurological dysfunction is still under investigation and the proposed causes are multi-faceted. The proposed etiologies are based on data from other coronaviruses as well as clinical observations, animal studies, and radiographic imaging. For example, SARS-CoV, as well as Middle Eastern Respiratory Syndrome (MERS) virus, have both been shown to cause neurological symptoms [4] and have also been observed in brain and CSF tissue [5]. Similarly, SARS-CoV-2 has been identified in central nervous system (CNS) tissue including the brainstem [6]. Inflammation, possibly as a result of a cytokine storm, may also contribute to neurological dysfunction [7]. This includes "smoldering", or low-grade inflammation, that does not produce clinical signs but may contribute to long-term dysfunction [8]. Inflammation may also compromise the blood-brain barrier and allow SARS-CoV-2 (or damaging substances) to access the CNS [9]. Infection with SARS-CoV-2 may 
also initiate protein aggregation via heparin-binding sites and/or spike-derived peptides, leading to amyloid fibrils that may produce similar pathology to Alzheimer's disease [10]. Elevated levels of amyloid-beta, neurofilament light, neurogranin, and tau in patients 1-3 months after recovery from COVID-19 suggest generation of neurotoxic proteins may contribute as well [11].

Other causes of neurological dysfunction in COVID-19 may be more indirect. For example, cerebral hypoxia and hypoperfusion due to respiratory dysfunction may cause neuronal damage $[12,13]$. COVID-19 may also exacerbate existing neurological disorders due to reallocation of resources and limited access to healthcare [14-16]. Intensive care unit (ICU) admission has been associated with long-term neurological effects and, given the high rates of ICU admission for SARS-CoV-2 [17], may also be a contributing cause. Residual pathology may also result from cardiovascular issues during acute illness, such as stroke $[4,18,19]$. Indeed, D-dimer, plasminogen activator inhibitor 1 (PAI-1), and Von Willebrand factor (VWF) are elevated in COVID-19 patients and may indicate hypercoagulable states and/or endothelial damage that can lead to stroke and other vascular complications [20-23]. SARS-CoV-2 may also induce host production of autoantibodies that can cause pathologies, such as Guillan-Barre syndrome [5]. Furthermore, Graham and colleagues found that a higher prevalence of autoimmune diseases and elevated anti-nuclear antibody (ANA) titers in patients with so-called "long COVID", suggesting an autoimmune component of disease [24].

Given the prevalence and seriousness of neurological illness associated with COVID-19, greater emphasis on the neurological sequelae of COVID-19 is needed. Here we discuss and summarize current observations from the literature regarding COVID-19 and neurological sequelae. We noted that in some cases these effects are correlated with COVID-19 illness and may not necessarily be the result of COVID-19 pathology. Nevertheless, while significantly more research is needed to elucidate the causes and persistent effects of a SARS-CoV-2 infection, we submit that this review provides important groundwork for researchers and clinicians moving forward.

\section{Main text \\ Methods}

The following terms and combinations of terms were searched in PubMed (https://pubmed.ncbi.nlm.nih. gov/) database for the following terms: "COVID-19" OR "long COVID" AND "brain", "chronic", "CNS", "cognition", "dementia", "Guillain-Barre", "headache", "long-term", "mechanism", "memory", "MRI", "neurological", "olfactory", "outcome", "Parkinson's", "recovery", "seizure", "sequelae", "stroke", and "taste". Filters for case reports, clinical study, observational study, and prospective study were occasionally used to focus results. Letters to the editor, brief commentaries, book chapters, and pre-prints were excluded. Results published or made available after July $15^{\text {th }}, 2021$ were excluded. Strictly psychiatric conditions such as depression and post-traumatic stress syndrome (PTSD) were excluded. As COVID-19 is an emerging disease, strict timeframes for defining neurological sequelae were not used. Consequences or complications were included based on persistence after either discharge, resolution of other COVID-19 symptoms, or designation as "long term" by study authors.

No ethical approval was obtained or required for the purposes of this review.

\section{Sensory}

Olfactory dysfunction (OD) and gustatory dysfunction (GD) are by far the most studied neurological symptoms of COVID-19 and have generated a tremendous number of clinical studies in a short timeframe. This may be due to both the rapidity of producing these studies (such as via patient surveys), the distinct relationship between OD and SARS-CoV-2, and the publicity surrounding COVID-19 and loss of smell. Indeed, loss of smell and taste is a clinical symptom of COVID-19, and loss of smell is considered a prodromal sign [25]. While the mechanism for olfactory dysfunction is unclear, high levels of SARS-CoV-2 have been observed in the nasal cavity [26] and it is proposed that SARS-CoV-2 can access the olfactory nerve via the angiotensin-converting enzyme 2 (ACE2) and transmembrane serine protease 2 (TMPRSS2) receptors on olfactory epithelium [27], with sensory neuron access via CD147 and neuropilin 1 (NRP1) receptors [28]. Damage to the olfactory nerve (or other tissues) may then occur via inflammation and vascular damage [5]. Reported sensations of "nasal burning" could suggest involvement of the trigeminal nerve [29]. ACE receptors have been widely discussed as a possible receptor in COVID-19 pathogenesis and their presence in CNS tissue may explain COVID-19 associated neurological disease [23, 30]. Furthermore, lower sensory impairment in children with COVID-19 may correlate with age-related expression of ACE2 [31]. Higher rates of OD have been observed in the United States and European populations compared to Asian populations which, given that differences in ACE expression have also been observed between these groups, supports the involvement of ACE2 receptors in OD [32, 33]. However, conflicting data regarding SARS-CoV-2 neuroinvasion exist [34] and some studies suggest olfactory epithelial damage may be the main cause of OD [35].

Central nervous system (CNS) involvement may also play a role in SARS-CoV-2 sensory impairment. The virus 
may gain access to CNS structures via the olfactory nerve $[36,37]$, blood, or leukocyte migration across the bloodbrain barrier [38]. SARS-CoV-2 can invade the olfactory bulb [39-41]. Magnetic resonance imaging (MRI) findings support a CNS etiology, with observations including olfactory cleft opacification [42] and enlarged olfactory structures (such as olfactory cortices and hippocampi) $[43,44]$ in COIVD-19 infected or recovering patients. However, rapid recovery of patients with OD suggests a non-neuronal cause, such as damage to olfactory epithelium cells [33, 45-47]. While there is significantly less discussion regarding the mechanism of $\mathrm{GD}$, it is proposed to occur via a similar mechanism (through ACE receptors in the tongue and oral cavity)[48] or via an increase in bradykinin levels [49].

Concomitant olfactory obstruction and rhinorrhea may obfuscate a unique SARS-CoV-2 contribution to OD, although several studies have found no correlation between these symptoms and OD [29, 42, 50-52]. Olfactory dysfunction has been reported with other coronavirus infections and epidemics, including the SARS-CoV virus [53], providing precedence for the OD caused by SARS-CoV-2. What's more, two studies found COVID-19 patients had a longer duration (10 vs. 15 days, $p<0.006)$ and lower recovery $(57.7 \%$ vs. $72.1 \%, p=0.027)$ than COVID-19 seronegative patients with olfactory dysfunction, suggesting that OD in COVID-19 has a unique etiology (although false negatives could complicate these results) [54, 55]. Therefore, while the exact etiology is unclear, it is likely that SARS-CoV-2 produces sensory impairment irrespective of other upper respiratory symptoms.

Sex and age differences have been reported, with some studies observing a higher incidence $(p<0.011)$ [50] and longer duration (26 vs. 14 days, $p=0.009$ ) of OD in females than males, including higher persistence at 4-6-week follow-up (OR 2.46, 95\% CI 1.46-4.13, $p=0.001)[49,55]$. Conversely, Amer and colleagues noted that females had better recovery at 1 month from COVID-19 onset ( $83.9 \%$ vs. $62.5 \%, p<0.005)$, proposing elevated androgens in males that enhance transcription of TMPRSS2 [56]. However, other studies have found no association between sex and OD/GD, making the association unclear [57-59]. Increased age ( $>55$ years) has also been associated with longer duration of GD (21.6 vs. 33.61 days, $p=0.019$ ) [60], whereas ages $>60$ years have been correlated with longer durations of OD $(p<0.001)$ [61].

Patients with sensory impairment have varying recovery times. OD symptoms typically resolve by $1-2$-month follow-up [58, 59, 62-66], although a range of recovery times have been reported, with some studies reporting a majority of patients recovering as early as approx. 2 weeks
$[67,68]$ and a minority of patients experiencing OD at 7-month follow-up [69]. Of interest are the minority of patients whose symptoms persist after several weeks [70, 71]. For example, Riestra-Ayora and colleagues noted persistence of OD in 11.2\% (14/125) patients at 6-month follow-up [72] and Nguyen and colleagues noted 24.0\% (30/125) 7 months after onset [69]. Timeframe for recovery from GD is similar to that for OD [62], although GD may resolve more rapidly in some instances [73]. In some rare cases (3/151), OD and GD symptoms have been found to reoccur (mean 19 days from initial resolution of symptoms) [74]. Parosmia has also been noted to occur later in the disease course, with Hopkins et al. showing a median onset of 2.5 months after onset of OD [75]. Indicators of sensory outcome have been observed, with increased severity of illness and persistence of symptoms OD and GD symptoms beyond 10 and 20 days, respectively, correlating with persistent dysfunctional illness $[59,76]$. However, Cho and colleagues found no correlation between recovery time based on viral loaded determined by polymerase chain reaction (PCR) [77].

Follow-up for OD and GD studies is usually performed using a questionnaire or using an olfactory/gustatory battery. While these studies are useful, they are nonetheless limited by the range and frequency of follow-up, participant subjectivity, interference of anosmia with gustatory function, and the subjectivity of self-rating systems, as well as an observed discrepancy between objective and self-reporting testing [78-80]. For example, it may have OD on objective testing but fail to perceive such on subjective testing, suggesting that studies that rely solely on self-reporting may underestimate recovery times [80] and vice versa [29].

Several treatments for olfactory dysfunction, typically involving a nasal corticosteroid have been performed with mixed results. For example, one study found betamethasone drops were not significant compared to placebo [81] but found to be significant when combined with ambroxol and rinazine [46]. Groups of patients in these trials are typically small, which may account for conflicting results between studies. Other treatments have shown potential, including fluticasone [82], although others, such as mometasone furate, oral steroids, and nasal irrigation have not $[63,83]$. The Clinical Olfactory Working Group currently supports olfactory training as a treatment, although notes that future research is needed for other therapies [84].

\section{Headache}

Headache is a non-specific clinical symptom that has been found to persist after acute COVID-19 infection and may occur in up to $63 \%$ of COVID-19 patients [85, 86]. Headache persistence beyond 30 days varies 
from $3.6 \%(5 / 139)$ [86] to $37.8 \%(28 / 74)$ [87]. However, among patients with symptoms persisting beyond 28 days $(\mathrm{n}=558)$ and 56 days $(\mathrm{n}=189)$, intermittent headaches were one of the most commonly reported symptoms at $91.2 \%$ and $93.7 \%$, respectively [88]. Furthermore, Caronna and colleagues noted that 50\% (14/28) of patients with persistent headaches had no prior history of headache. Nevertheless, the mechanisms for headaches are unknown but proposed to include elevated cytokines and chemokines [87, 89], activation of trigeminal nerve branches, and ACE2 interaction in cerebral blood vessels [87]. Pediatric patients, a population not normally considered with COVID-19, may have neurological sequelae, such as headache and difficulties with concentration, although the evidence is limited [90,91].

\section{Cognition and memory}

Cognition and memory can be chronically affected by COVID-19. Miskowiak and colleagues found an association between cognitive impairments and D-dimer levels during the acute phase of illness [12], supporting previous studies that use of heparin and tissue plasminogen activator (tPA) may improve outcomes [92, 93]. Cognitive recovery varies, with some studies showing significant recovery in the majority of COVID-19 patients at 1 month [94, 95], with Rass and colleagues found that $23 \%$ of studied patients had cognitive defects (measured by Montreal Cognitive Assessment) at 3-month follow-up. This was increased to $50 \%$ among those who had encephalopathy during COVID-19 illness [79]. McLoughlin et al. found that, among previously hospitalized adult patients with COVID-19, cognition at 4-week follow-up (measured using the modified Telephone Instrument for Cognitive Status) was similar to those without delirium. However, physical function (as measured by combined Barthel Index and Nottingham Extended Activities of Living scores) was markedly worse in those with delirium (97 vs. 153, $p<0.01$ ) [96]. Furthermore, higher rates of dementia were observed among COVID-19 survivors compared to those with influenza (HR 2.33; 95\% CI 1.773.07; $p<0.0001$ ) or other respiratory infections (HR 1.71; 95\% CI 1.50-1.95) [97]. Interestingly, van der Borst and colleagues, in a study of 124 COVID-19 patients (46 with severe or critical disease), found that mental or cognitive function was not correlated with disease severity via the Clinical Frailty Scale [98]. Conversely, a study of 120 participants with mild-moderate COVID-19 observed that $98.3 \%(118 / 120)$ had normal cognitive functioning at 4-month follow-up. However, this group had a relatively low rate of comorbidities (15\% hypertension, $8.3 \%$ obesity, $3.3 \%$ diabetes) and rarely received supplementary oxygen therapy (1.6\%) [99]. Finally, inpatient rehabilitation was associated with significant improvement in memory and cognitive function in a cohort $(n=29)$ of hospitalized COVID-19 patients (mean hospital and intubation length 32.2 and 18.7 days, respectively), with $90 \%$ of patients discharged home after a mean of 16.7 of inpatient rehab [100], suggesting the importance of such care in recovery from COVID-19.

There is also concern that COVID-19 may cause or worsen neurological diseases, such as Alzheimer's. For example, apolipoprotein E (ApoE) e4e4 allele, highly associated with Alzheimer's, may increase the risk of severe COVID-19 [101]. Risk for Alzheimer's might be indirectly increased due to respiratory dysfunction, as tau hyperphosphorylation is increased by hypoxia [102]. Alzheimer's patients could be more vulnerable to COVID-19 given increased ACE expression in brains of Alzheimer's patients has been observed [9]; tau hyperphosphorylation increased due to hypoxia.

\section{Other neurological disorders}

Several other neurological conditions have been reported in COVID-19 patients. Cavalagli and colleagues reported cranial nerve V3, IX, X, and XII impairment with gradual recovery over 2 months in a 69-year-old male [103]. Akinetic mutism and transient non-specific frontal release signs have been reported in 13.1\% (8/61) of COVID-19 ICU patients at 3-month follow-up [104]. COVID-19 may also negatively affect quality of sleep. Rass and colleagues noted that $34 \%(n=135)$ of patients had sleep disturbances at 3-month follow-up, with higher rates among ICU patients $(43 \%, n=31)$. The authors note that fatigue was more frequent in patients with sleep disturbances (adjOR 6.39; 95\% CI 2.63-15.53, $p<0.001$ ), which may partially explain fatigue observed in "long COVID" patients. Sleep disturbance was also associated with new neurological disease (adjOR 5.71; 95\% CI 1.76-18.54; $p=0.004$ ) [79]. Huang and colleagues, in a large survey of discharged COVID-19 patients, observed 2\% (437/1655) of patients had sleep difficulties at 6-month follow-up, with similar rates for those requiring $(26 \% ; 290 / 1114)$ and not requiring (27\%; 116/424) supplemental oxygen [105].

Stroke and COVID-19 are of concern due to hypercoagulable states induced by COVID-19 infection [106] and possible infection of vasculoendothelial cells [23, 38]. Furthermore, limitations in health resources due to the pandemic, suggested by markedly decreased rates of stroke admission and emergency care early in the pandemic, may also indirectly contribute to long-term effects of stroke in non-COVID-19 patients [107, 108]. Given that stroke can be neurologically devastating, monitoring for stroke and stroke prevention may need to be considered in at-risk COVID-19 patients. COVID-19 may also longitudinally impact patients with Parkinson's disease, although the evidence is limited. Leta and colleagues 
observed "post-COVID syndrome" (defined as symptoms persisting beyond 12 weeks) in 27 patients with Parkinson's, noting worsening motor function (51.9\%) and increased levodopa requirements (48.2\%) [109]. Finally, there have been a number of Guillain-Barre (GBS) cases associated with COVID-19, with one study identifying over 70 cases $[19,110]$, although a causal link has not been established. A multi-center Italian study noted a 2.6 fold increased in GBS cases in March and April of 2020 compared to the same period in 2019 and estimated GBS incidence among COVID-19 positive patients (47.9/100,000/year) and COVID-19 positive hospitalized patients (236/100,000/year) [111]. Abu-Rumeileh and colleagues noted a wide age range of affected patients (11-94 years, mean 55 years) with male predominance [110] Furthermore, demyelinating lesions have been observed in the brain and spinal cord on CT and MRI, possibly from an autoimmune etiology similar to GBS or multiple sclerosis [112]. Given that recovery from Guillain-Barre can take months to years [113], the effects of secondary illnesses associated with COVID-19 can be potentially devastating.

\section{Conclusions}

The long-term neurological complications of COVID-19 are varied and still poorly understood. While many studies have assessed the clinical impact of COVID-19 on the nervous system, most of these are limited in scope. Many studies have follow-up times less than 3 months, have limited number of patients (such as case reports or case series), and use surveys instead of clinical or radiological assessments. We also note that many proposed mechanisms of COVID-19 neuropathology are theoretical and not based on empirical evidence. While these initial clinical observations and proposed mechanisms provide useful starting points for future research, they are neither sufficient nor definitive. Long-term prospective studies employing sensory and radiological assessments will be crucial for assessing the impact and progression of long-term COVID-19 neurological symptoms. While the long-term impact of COVID-19 is still undetermined, clinicians should be aware of possible outcomes and etiologies when caring for patients recovering from this virus.

\footnotetext{
Abbreviations

COVID-19: Coronavirus disease 2019; SARS-CoV-2: Severe acute respiratory syndrome coronavirus 2; MERS: Middle eastern respiratory syndrome; CNS: Central nervous system; SARS-CoV: Severe acute respiratory syndrome; ICU: Intensive care unit; ANA: Anti-nuclear antibody; MRI: Magnetic resonance imaging; OD: Olfactory dysfunction; GD: Gustatory dysfunction; ACE: Angiotensin-converting enzyme; TMPRSS2: Transmembrane serine protease 2; PCR: Polymerase chain reaction; tPA: Tissue plasminogen activator; ApoE: Apolipoprotein E; GBS: Guillain-Barre syndrome; CT: Computed tomography; MRI: Magnet resonance imaging; adjOR: Adjusted odds ratio; OR: Odds ratio; HR: Hazard ratio; Cl: Confidence interval.
}

\section{Acknowledgements}

None.

\section{Authors' contributions}

$C P$, literature search, analysis, and manuscript synthesis; AS, manuscript synthesis and editing, and expert opinion; FB, literature search, wrote abstract and methods sections. All authors read and approved the final manuscript.

\section{Funding \\ None.}

\section{Availability of data and materials}

Data sharing is not applicable to this article as no data sets were generated or analyzed during the current study.

\section{Declarations}

Ethics approval and consent to participate N/A.

\section{Consent for publication}

$\mathrm{N} / \mathrm{A}$

\section{Competing interests}

The authors report no competing interests.

\section{Author details}

${ }^{1}$ Menninger Department of Psychiatry, Baylor College of Medicine, One Baylor Plaza, Houston, TX 77030, USA. ${ }^{2}$ Department of Psychiatry, Texas Tech University Health Sciences Center, 3601 4th St., Lubbock, TX 79430, USA. ${ }^{3}$ SUNY Upstate Medical University, 750E Adams St, Syracuse, NY 13210, USA.

Received: 16 June 2021 Accepted: 26 August 2021

Published online: 08 September 2021

\section{References}

1. Paterson RW, Brown RL, Benjamin L, Nortley R, Wiethoff S, Bharucha T, et al. The emerging spectrum of COVID-19 neurology: clinical, radiological and laboratory findings. Brain. 2020;143(10):3104-20. https://doi. org/10.1093/brain/awaa240.

2. Liguori C, Pierantozzi M, Spanetta M, Sarmati L, Cesta N, lannetta M, et al. Subjective neurological symptoms frequently occur in patients with SARS-CoV2 infection. Brain Behav Immun. 2020;88:11-6. https:// doi.org/10.1016/j.bbi.2020.05.037.

3. Qin Y, Wu J, Chen T, Li J, Zhang G, Wu D, et al. Long-term microstructure and cerebral blood flow changes in patients recovered from COVID-19 without neurological manifestations. J Clin Invest. 2021. https://doi.org/ 10.1172/jci147329.

4. Andrabi MS, Andrabi SA. Neuronal and cerebrovascular complications in coronavirus disease 2019. Front Pharmacol. 2020;11: 570031. https:// doi.org/10.3389/fphar.2020.570031.

5. Al-Ramadan A, Rabab'h O, Shah J, Gharaibeh A. Acute and post-acute neurological complications of COVID-19. Neurol Int. 2021;13(1):102-19. https://doi.org/10.3390/neurolint13010010.

6. Yong SJ. Persistent brainstem dysfunction in long-COVID: a hypothesis. ACS Chem Neurosci. 2021;12(4):573-80. https://doi.org/10.1021/acsch emneuro.0c00793.

7. Fiani B, Covarrubias C, Desai A, Sekhon M, Jarrah R. A contemporary review of neurological sequelae of COVID-19. Front Neurol. 2020;11:640 https://doi.org/10.3389/fneur.2020.00640.

8. Baig AM. Deleterious outcomes in long-hauler COVID-19: the effects of SARS-CoV-2 on the CNS in chronic COVID syndrome. ACS Chem Neurosci. 2020;11(24):4017-20. https://doi.org/10.1021/acschemneuro. 0c00725.

9. Ciaccio M, Lo Sasso B, Scazzone C, Gambino CM, Ciaccio AM, Bivona G, et al. COVID-19 and Alzheimer's disease. Brain Sci. 2021. https://doi.org/ 10.3390/brainsci11030305. 
10. Tavassoly O, Safavi F, Tavassoly I. Seeding brain protein aggregation by SARS-CoV-2 as a possible long-term complication of COVID-19 infection. ACS Chem Neurosci. 2020;11(22):3704-6. https://doi.org/10.1021/ acschemneuro.0c00676.

11. Sun B, Tang N, Peluso MJ, lyer NS, Torres L, Donatelli JL, et al. Characterization and biomarker analyses of post-COVID-19 complications and neurological manifestations. Cells. 2021;10(2):386. https://doi.org/10 3390/cells10020386.

12. Miskowiak KW, Johnsen S, Sattler SM, Nielsen S, Kunalan K, Rungby J, et al. Cognitive impairments four months after COVID-19 hospital discharge: pattern, severity and association with illness variables. Eur Neuropsychopharmacol. 2021;46:39-48. https://doi.org/10.1016/j. euroneuro.2021.03.019.

13. Helms J, Kremer S, Merdji H, Clere-Jehl R, Schenck M, Kummerlen C, et al. Neurologic features in severe SARS-CoV-2 infection. N Engl J Med. 2020;382(23):2268-70. https://doi.org/10.1056/NEJMc2008597.

14. lodice F, Cassano V, Rossini PM. Direct and indirect neurological, cognitive, and behavioral effects of COVID-19 on the healthy elderly, mildcognitive-impairment, and Alzheimer's disease populations. Neurol Sci. 2021;42(2):455-65. https://doi.org/10.1007/s10072-020-04902-8

15. Shalash A, Roushdy T, Essam M, Fathy M, Dawood NL, Abushady EM, et al. Mental health, physical activity, and quality of life in Parkinson's disease during COVID-19 pandemic. Mov Disord. 2020;35(7):1097-9. https://doi.org/10.1002/mds.28134.

16. Roushdy TM, Nahas NME, Aref HM, Georgy SS, Zaki AS, Bedros RY, et al. Stroke in the time of coronavirus disease 2019: experience of two university stroke centers in Egypt. J Stroke. 2020;22(2):275-7. https:// doi.org/10.5853/jos.2020.01550.

17. Abate SM, Ahmed Ali S, Mantfardo B, Basu B. Rate of intensive care unit admission and outcomes among patients with coronavirus: a systematic review and meta-analysis. PLoS ONE. 2020;15(7):e035653-e. https:// doi.org/10.1371/journal.pone.0235653.

18. Diaz-Segarra N, Edmond A, Kunac A, Yonclas P. COVID-19 ischemic strokes as an emerging rehabilitation population: a case series. Am J Phys Med Rehabil. 2020;99(10):876-9. https://doi.org/10.1097/phm. 0000000000001532

19. Schweitzer F, Kleineberg NN, Göreci Y, Onur OA, Franke C, Warnke C. Neuro-COVID-19 is more than anosmia: clinical presentation, neurodiagnostics, therapies, and prognosis. Curr Opin Neurol. 2021. https://doi. org/10.1097/wco.0000000000000930.

20. Karadaş Ö, Öztürk B, Sonkaya AR. A prospective clinical study of detailed neurological manifestations in patients with COVID-19. Neurol Sci. 2020;41(8):1991-5. https://doi.org/10.1007/s10072-020-04547-7.

21. Huang C, Wang Y, Li X, Ren L, Zhao J, Hu Y, et al. Clinical features of patients infected with 2019 novel coronavirus in Wuhan, China. Lancet. 2020;395(10223):497-506. https://doi.org/10.1016/s0140-6736(20) 30183-5.

22. Mao L, Jin H, Wang M, Hu Y, Chen S, He Q, et al. Neurologic manifestations of hospitalized patients with coronavirus disease 2019 in Wuhan, China. JAMA Neurol. 2020;77(6):683-90. https://doi.org/10.1001/jaman eurol.2020.1127.

23. Roushdy T, Hamid E. A review on SARS-CoV-2 and stroke pathogenesis and outcome. Egypt J Neurol Psychiatr Neurosurg. 2021;57(1):63. https://doi.org/10.1186/s41983-021-00319-y.

24. Graham EL, Clark JR, Orban ZS, Lim PH, Szymanski AL, Taylor C, et al. Persistent neurologic symptoms and cognitive dysfunction in non-hospitalized Covid-19"long haulers." Ann Clin Transl Neurol. 2021;8(5):1073-85. https://doi.org/10.1002/acn3.51350.

25. Pereira A. Long-term neurological threats of COVID-19: a call to update the thinking about the outcomes of the coronavirus pandemic. Front Neurol. 2020;11:308. https://doi.org/10.3389/fneur.2020.00308.

26. Speth MM, Singer-Cornelius T, Oberle M, Gengler I, Brockmeier SJ, Sedaghat AR. Olfactory dysfunction and sinonasal symptomatology in COVID-19: prevalence, severity, timing, and associated characteristics. Otolaryngol Head Neck Surg. 2020;163(1):114-20. https://doi.org/10. 1177/0194599820929185.

27. Wang F, Kream RM, Stefano GB. Long-term respiratory and neurological sequelae of COVID-19. Med Sci Monit. 2020;26: e928996. https://doi. org/10.12659/msm.928996.

28. Septyaningtrias DE, Susilowati R. Neurological involvement of COVID19: from neuroinvasion and neuroimmune crosstalk to long-term consequences. Rev Neurosci. 2021. https://doi.org/10.1515/revne uro-2020-0092.

29. Lechien JR, Chiesa-Estomba CM, De Siati DR, Horoi M, Le Bon SD, Rodriguez A, et al. Olfactory and gustatory dysfunctions as a clinical presentation of mild-to-moderate forms of the coronavirus disease (COVID-19): a multicenter European study. Eur Arch Otorhinolaryngol. 2020:277(8):2251-61. https://doi.org/10.1007/s00405-020-05965-1.

30. Chen R, Wang K, Yu J, Howard D, French L, Chen Z, et al. The spatial and cell-type distribution of SARS-COV-2 receptor ACE2 in the human and mouse brains. Front Neurol. 2020;11: 573095. https://doi.org/10.3389/ fneur.2020.573095.

31. Somekh I, Yakub Hanna H, Heller E, Bibi H, Somekh E. Age-dependent sensory impairment in COVID-19 infection and its correlation with ACE2 expression. Pediatr Infect Dis J. 2020;39(9):e270-2. https://doi.org/ 10.1097/inf.0000000000002817.

32. Cao Y, Li L, Feng Z, Wan S, Huang P, Sun X, et al. Comparative genetic analysis of the novel coronavirus (2019-nCoV/SARS-CoV-2) receptor ACE2 in different populations. Cell Discov. 2020;6(1):11. https://doi.org/ 10.1038/s41421-020-0147-1.

33. Kumar L, Kahlon N, Jain A, Kaur J, Singh M, Pandey AK. Loss of smell and taste in COVID-19 infection in adolescents. Int J Pediatr Otorhinolaryngol. 2021;142: 110626. https://doi.org/10.1016/j.ijporl.2021.110626.

34. Hassett CE, Frontera JA. Neurologic aspects of coronavirus disease of 2019 infection. Curr Opin Infect Dis. 2021;34(3):217-27. https://doi.org/ 10.1097/qco.0000000000000731.

35. Vaira LA, Hopkins C, Sandison A, Manca A, Machouchas N, Turilli D, et al. Olfactory epithelium histopathological findings in long-term coronavirus disease 2019 related anosmia. J Laryngol Otol. 2020;134(12):1123-7. https://doi.org/10.1017/S0022215120002455.

36. Wang F, Kream RM, Stefano GB. Long-term respiratory and neurological sequelae of COVID-19. Med Sci Monit. 2020;26:928996. https://doi.org/ 10.12659/MSM.928996

37. Niazkar HR, Zibaee B, Nasimi A, Bahri N. The neurological manifestations of COVID-19: a review article. Neurol Sci. 2020;41(7):1667-71. https:// doi.org/10.1007/s10072-020-04486-3.

38. Zubair AS, McAlpine LS, Gardin T, Farhadian S, Kuruvilla DE, Spudich S. Neuropathogenesis and neurologic manifestations of the coronaviruses in the age of coronavirus disease 2019: a review. JAMA Neurol. 2020;77(8):1018-27. https://doi.org/10.1001/jamaneurol.2020.2065.

39. Anwar MM, Badawi AM, Eltablawy NA. Can the coronavirus infection penetrates the brain resulting in sudden anosmia followed by severe neurological disorders? eNeurologicalSci. 2020;21:100290. https://doi. org/10.1016/j.ensci.2020.100290.

40. Morbini P, Benazzo M, Verga L, Pagella FG, Mojoli F, Bruno R, et al. Ultrastructural evidence of direct viral damage to the olfactory complex in patients testing positive for SARS-CoV-2. JAMA Otolaryngol Head Neck Surg. 2020;146(10):972-3. https://doi.org/10.1001/jamaoto.2020.2366.

41. Meinhardt J, Radke J, Dittmayer C, Franz J, Thomas C, Mothes R, et al. Olfactory transmucosal SARS-CoV-2 invasion as a port of central nervous system entry in individuals with COVID-19. Nat Neurosci. 2021:24(2):168-75. https://doi.org/10.1038/s41593-020-00758-5.

42. Kandemirli SG, Altundag A, Yildirim D, Tekcan Sanli DE, Saatci O. Olfactory bulb MRI and paranasal sinus CT Findings in persistent COVID-19 anosmia. Acad Radiol. 2021;28(1):28-35. https://doi.org/10.1016/j.acra. 2020.10.006.

43. LuY, Li X, Geng D, Mei N, Wu PY, Huang CC, et al. Cerebral micro-structural changes in COVID-19 patients - an MRI-based 3-month follow-up study. EClinicalMedicine. 2020;25: 100484. https://doi.org/10.1016/j. eclinm.2020.100484.

44. Altundag A, Yıldırım D, Tekcan Sanli DE, Cayonu M, Kandemirli SG, Sanli AN, et al. Olfactory cleft measurements and COVID-19-related anosmia. Otolaryngol Head Neck Surg. 2021;164(6):1337-44. https://doi.org/10. 1177/0194599820965920.

45. Vaira LA, Salzano G, Fois AG, Piombino P, De Riu G. Potential pathogenesis of ageusia and anosmia in COVID-19 patients. Int Forum Allergy Rhinol. 2020;10(9):1103-4. https://doi.org/10.1002/alr.22593.

46. Vaira LA, Hopkins C, Petrocelli M, Lechien JR, Cutrupi S, Salzano G, et al. Efficacy of corticosteroid therapy in the treatment of long- lasting olfactory disorders in COVID-19 patients. Rhinology. 2021;59(1):21-5. https:// doi.org/10.4193/Rhin20.515. 
47. Kacem I, Gharbi A, Harizi C, Souissi E, Safer M, Nasri A, et al. Characteristics, onset, and evolution of neurological symptoms in patients with COVID-19. Neurol Sci. 2021;42(1):39-46. https://doi.org/10.1007/ s10072-020-04866-9.

48. Kanjanaumporn J, Aeumjaturapat S, Snidvongs K, Seresirikachorn K Chusakul S. Smell and taste dysfunction in patients with SARS-CoV-2 infection: a review of epidemiology, pathogenesis, prognosis, and treatment options. Asian Pac J Allergy Immunol. 2020;38(2):69-77. https:// doi.org/10.12932/ap-030520-0826.

49. Meini S, Suardi LR, Busoni M, Roberts AT, Fortini A. Olfactory and gustatory dysfunctions in 100 patients hospitalized for COVID-19: sex differences and recovery time in real-life. Eur Arch Oto-Rhinol. 2020;277(12):3519-23. https://doi.org/10.1007/s00405-020-06102-8.

50. Ramasamy K, Saniasiaya J, Abdul GN. Olfactory and gustatory dysfunctions as a clinical manifestation of coronavirus disease 2019 in a Malaysian tertiary center. Ann Otol Rhinol Laryngol. 2021;130(5):513-9. https://doi.org/10.1177/0003489420963165.

51. Printza A, Katotomichelakis M, Valsamidis K, Metallidis S, Panagopoulos P, Panopoulou $M$, et al. Smell and taste loss recovery time in COVID-19 patients and disease severity. J Clin Med. 2021. https://doi.org/10.3390/ jcm10050966.

52. Jalessi M, Barati M, Rohani M, Amini E, Ourang A, Azad Z, et al. Frequency and outcome of olfactory impairment and sinonasal involvement in hospitalized patients with COVID-19. Neurol Sci. 2020:41(9):2331-8. https://doi.org/10.1007/s10072-020-04590-4.

53. Meng X, Deng Y, Dai Z, Meng Z. COVID-19 and anosmia: a review based on up-to-date knowledge. Am J Otolaryngol. 2020;41(5):102581. https://doi.org/10.1016/j.amjoto.2020.102581.

54. Kosugi EM, Lavinsky J, Romano FR, Fornazieri MA, Luz-Matsumoto GR, Lessa MM, et al. Incomplete and late recovery of sudden olfactory dysfunction in COVID-19. Braz J Otorhinolaryngol. 2020;86(4):490-6. https://doi.org/10.1016/j.bjorl.2020.05.001.

55. Makaronidis J, Firman C, Magee CG, Mok J, Balogun N, Lechner M, et al. Distorted chemosensory perception and female sex associate with persistent smell and/or taste loss in people with SARS-CoV-2 antibodies: a community based cohort study investigating clinical course and resolution of acute smell and/or taste loss in people with and without SARS-CoV-2 antibodies in London, UK. BMC Infect Dis. 2021:21(1):221. https://doi.org/10.1186/s12879-021-05927-w

56. Amer MA, Elsherif HS, Abdel-Hamid AS, Elzayat S. Early recovery patterns of olfactory disorders in COVID-19 patients; a clinical cohort study. Am J Otolaryngol. 2020;41(6):102725. https://doi.org/10.1016/j.amjoto. 2020.102725.

57. Salcan I, Karakeçili F, Salcan S, Ünver E, Akyüz S, Seçkin E, et al. Is taste and smell impairment irreversible in COVID-19 patients? Eur Arch Otorhinolaryngol. 2021;278(2):411-5. https://doi.org/10.1007/ s00405-020-06560-0.

58. lannuzzi L, Salzo AE, Angarano G, Palmieri VO, Portincasa P, Saracino A, et al. Gaining back what is lost: recovering the sense of smell in mild to moderate patients after COVID-19. Chem Senses. 2020;45(9):875-81. https://doi.org/10.1093/chemse/bjaa066.

59. Samimi Ardestani SH, Mohammadi Ardehali M, Rabbani Anari M, Rahmaty B, Erfanian R, Akbari M, et al. The coronavirus disease 2019: the prevalence, prognosis, and recovery from olfactory dysfunction (OD). Acta Otolaryngol. 2021;141(2):171-80. https://doi.org/10.1080/00016 489.2020.1836397.

60. Antolín-Amérigo D, Cubero JL, Colás C, Alobid I, Mullol J, Valero A. High frequency of smell and taste dysfunctions in allergy health care professionals suffering from COVID-19. J Investig Allergol Clin Immunol. 2021. https://doi.org/10.18176/jiaci.0670.

61. Lee Y, Min P, Lee S, Kim SW. Prevalence and duration of acute loss of smell or taste in COVID-19 patients. J Korean Med Sci. 2020;35(18): e174. https://doi.org/10.3346/jkms.2020.35.e174.

62. Brandão Neto D, Fornazieri MA, Dib C, Di Francesco RC, Doty RL, Voegels RL, et al. Chemosensory dysfunction in COVID-19: prevalences, recovery rates, and clinical associations on a large Brazilian sample. Otolaryngol Head Neck Surg. 2021;164(3):512-8. https://doi.org/10. 1177/0194599820954825

63. Chiesa-Estomba CM, Lechien JR, Radulesco T, Michel J, Sowerby LJ, Hopkins C, et al. Patterns of smell recovery in 751 patients affected by the COVID-19 outbreak. Eur J Neurol. 2020;27(11):2318-21. https://doi. org/10.1111/ene.14440.

64. Thakur K, Sagayaraj A, Prasad KC, Gupta A. Olfactory dysfunction in COVID-19 patients: findings from a tertiary rural centre. Indian J Otolaryngol Head Neck Surg. 2021. https://doi.org/10.1007/ s12070-021-02364-8.

65. Reiter ER, Coelho DH, Kons ZA, Costanzo RM. Subjective smell and taste changes during the COVID-19 pandemic: Short term recovery. Am J Otolaryngol. 2020;41(6): 102639. https://doi.org/10.1016/j.amjoto.2020. 102639.

66. Karthikeyan P, Sivanand N, Vijayan N, Latheef MN. A clinical study of smell disorders in COVID-19 patients in a tertiary care hospital in Pondicherry: a cross sectional study. Indian J Otolaryngol Head Neck Surg. 2021. https://doi.org/10.1007/s12070-021-02499-8.

67. Chary E, Carsuzaa F, Trijolet JP, Capitaine AL, Roncato-Saberan M, Fouet $\mathrm{K}$, et al. Prevalence and recovery from olfactory and gustatory dysfunctions in COVID-19 Infection: a prospective multicenter study. Am J Rhinol Allergy. 2020;34(5):686-93. https://doi.org/10.1177/1945892420 930954.

68. Paolo G. Does COVID-19 cause permanent damage to olfactory and gustatory function? Med Hypotheses. 2020;143: 110086. https://doi. org/10.1016/j.mehy.2020.110086.

69. Nguyen NN, Hoang VT, Lagier J-C, Raoult D, Gautret P. Long-term persistence of olfactory and gustatory disorders in COVID-19 patients. Clin Microbiol Infect. 2021;27(6):931-2. https://doi.org/10.1016/j.cmi.2020. 12.021.

70. LaVergne SM, Stromberg S, Baxter BA, Webb TL, Dutt TS, Berry K, et al. A longitudinal SARS-CoV-2 biorepository for COVID-19 survivors with and without post-acute sequelae. BMC Infect Dis. 2021;21(1):677. https:// doi.org/10.1186/s12879-021-06359-2.

71. Biadsee A, Dagan O, Ormianer Z, Kassem F, Masarwa S, Biadsee A. Eightmonth follow-up of olfactory and gustatory dysfunctions in recovered COVID-19 patients. Am J Otolaryngol. 2021;42(4): 103065. https://doi. org/10.1016/j.amjoto.2021.103065.

72. Riestra-Ayora J, Yanes-Diaz J, Esteban-Sanchez J, Vaduva C, MolinaQuiros C, Larran-Jimenez A, et al. Long-term follow-up of olfactory and gustatory dysfunction in COVID-19: 6 months case-control study of health workers. Eur Arch Oto-Rhinol. 2021. https://doi.org/10.1007/ s00405-021-06764-y.

73. Cousyn L, Sellem B, Palich R, Bendetowicz D, Agher R, Delorme C, et al Olfactory and gustatory dysfunctions in COVID-19 outpatients: a prospective cohort study. Infect Dis Now. 2021. https://doi.org/10.1016/j. idnow.2021.03.004

74. Paderno A, Mattavelli D, Rampinelli V, Grammatica A, Raffetti E, Tomasoni $\mathrm{M}$, et al. Olfactory and gustatory outcomes in COVID-19: a prospective evaluation in nonhospitalized subjects. Otolaryngol Head Neck Surg. 2020;163(6):1144-9. https://doi.org/10.1177/0194599820939538.

75. Hopkins C, Surda P, Vaira LA, Lechien JR, Safarian M, Saussez S, et al. Six month follow-up of self-reported loss of smell during the COVID-19 pandemic. Rhinology. 2021;59(1):26-31. https://doi.org/10.4193/ Rhin20.544.

76. Vaira LA, Hopkins C, Petrocelli M, Lechien JR, Chiesa-Estomba CM, Salzano G, et al. Smell and taste recovery in coronavirus disease 2019 patients: a 60-day objective and prospective study. J Laryngol Otol. 2020;134(8):703-9. https://doi.org/10.1017/s0022215120001826.

77. Cho RHW, To ZWH, Yeung ZWC, Tso EYK, Fung KSC, Chau SKY, et al. COVID-19 viral load in the severity of and recovery from olfactory and gustatory dysfunction. Laryngoscope. 2020;130(11):2680-5. https://doi. org/10.1002/lary.29056.

78. Le Bon SD, Pisarski N, Verbeke J, Prunier L, Cavelier G, Thill MP, et al Psychophysical evaluation of chemosensory functions 5 weeks after olfactory loss due to COVID-19: a prospective cohort study on 72 patients. Eur Arch Otorhinolaryngol. 2021;278(1):101-8. https://doi.org/ 10.1007/s00405-020-06267-2.

79. Rass V, Beer R, Josef Schiefecker A, Kofler M, Lindner A, Mahlknecht $P$, et al. Neurological outcome and quality of life three months after COVID-19: a prospective observational cohort study. Eur J Neurol. 2021. https://doi.org/10.1111/ene.14803.

80. Otte MS, Eckel HNC, Poluschkin L, Klussmann JP, Luers JC. Olfactory dysfunction in patients after recovering from COVID-19. Acta Otolaryngol. 2020;140(12):1032-5. https://doi.org/10.1080/00016489.2020.1811999. 
81. Rashid RA, Zgair A, Al-Ani RM. Effect of nasal corticosteroid in the treatment of anosmia due to COVID-19: a randomised double-blind placebo-controlled study. Am J Otolaryngol. 2021;42(5): 103033. https://doi.org/10.1016/j.amjoto.2021.103033.

82. Singh CV, Jain S, Parveen S. The outcome of fluticasone nasal spray on anosmia and triamcinolone oral paste in dysgeusia in COVID-19 patients. Am J Otolaryngol. 2021;42(3): 102892. https://doi.org/10. 1016/j.amjoto.2020.102892.

83. Abdelalim AA, Mohamady AA, Elsayed RA, Elawady MA, Ghallab AF. Corticosteroid nasal spray for recovery of smell sensation in COVID-19 patients: a randomized controlled trial. Am J Otolaryngol. 2021;42(2): 102884. https://doi.org/10.1016/j.amjoto.2020.102884.

84. Addison AB, Wong B, Ahmed T, Macchi A, Konstantinidis I, Huart C, et al. Clinical Olfactory Working Group consensus statement on the treatment of postinfectious olfactory dysfunction. J Allergy Clin Immunol. 2021;147(5):1704-19. https://doi.org/10.1016/j.jaci.2020.12.641.

85. Harapan BN, Yoo HJ. Neurological symptoms, manifestations, and complications associated with severe acute respiratory syndrome coronavirus 2 (SARS-CoV-2) and coronavirus disease 19 (COVID-19). J Neurol. 2021. https://doi.org/10.1007/s00415-021-10406-y.

86. Poncet-Megemont L, Paris P, Tronchere A, Salazard JP, Pereira B, Dallel $R$, et al. High prevalence of headaches during covid-19 infection: a retrospective cohort study. Headache. 2020;60(10):2578-82. https://doi. org/10.1111/head.13923.

87. Caronna E, Ballvé A, Llauradó A, Gallardo VJ, Ariton DM, Lallana S, et al. Headache: a striking prodromal and persistent symptom, predictive of COVID-19 clinical evolution. Cephalalgia. 2020;40(13):1410-21. https:// doi.org/10.1177/0333102420965157.

88. Sudre CH, Murray B, Varsavsky T, Graham MS, Penfold RS, Bowyer RC, et al. Attributes and predictors of long COVID. Nat Med. 2021;27(4):62631. https://doi.org/10.1038/s41591-021-01292-y.

89. Trigo J, García-Azorín D, Sierra-Mencía Á, Tamayo-Velasco Á, MartínezPaz P, Tamayo E, et al. Cytokine and interleukin profile in patients with headache and COVID-19: a pilot, case-control, study on 104 patients. J Headache Pain. 2021;22(1):51. https://doi.org/10.1186/ s10194-021-01268-w.

90. Ludvigsson JF. Case report and systematic review suggest that children may experience similar long-term effects to adults after clinical COVID19. Acta Paediatr. 2021;110(3):914-21. https://doi.org/10.1111/apa. 15673.

91. Pantelis C, Jayaram M, Hannan AJ, Wesselingh R, Nithianantharajah J, Wannan CMJ, et al. Neurological, neuropsychiatric and neurodevelopmental complications of COVID-19. Aust N Z J Psychiatry. 2020. https:// doi.org/10.1177/0004867420961472

92. Tang N, Bai H, Chen X, Gong J, Li D, Sun Z. Anticoagulant treatment is associated with decreased mortality in severe coronavirus disease 2019 patients with coagulopathy. J Thromb Haemost. 2020;18(5):1094-9. https://doi.org/10.1111/jth.14817.

93. Christie DBI, Nemec HM, Scott AM, Buchanan JT, Franklin CM, Ahmed A, et al. Early outcomes with utilization of tissue plasminogen activator in COVID-19-associated respiratory distress: a series of five cases. J Trauma Acute Care Surg. 2020;89(3):448-52. https://doi.org/10.1097/ta.00000 00000002787.

94. Monti G, Leggieri C, Fominskiy E, Scandroglio AM, Colombo S, Tozzi M, et al. Two-months quality of life of COVID-19 invasively ventilated survivors; an Italian single-center study. Acta Anaesthesiol Scand. 2021. https://doi.org/10.1111/aas.13812.

95. Alemanno F, Houdayer E, Parma A, Spina A, Del Forno A, Scatolini A, et al. COVID-19 cognitive deficits after respiratory assistance in the subacute phase: a COVID-rehabilitation unit experience. PLOS ONE. 2021;16(2): e0246590. https://doi.org/10.1371/journal.pone.0246590.

96. McLoughlin BC, Miles A, Webb TE, Knopp P, Eyres C, Fabbri A, et al. Functional and cognitive outcomes after COVID-19 delirium. Eur Geriatr Med. 2020;11(5):857-62. https://doi.org/10.1007/s41999-020-00353-8.

97. Taquet M, Geddes JR, Husain M, Luciano S, Harrison PJ. 6-month neurological and psychiatric outcomes in 236379 survivors of COVID-19: a retrospective cohort study using electronic health records. Lancet Psychiatry. 2021;8(5):416-27. https://doi.org/10.1016/s2215-0366(21) 00084-5.
98. van den Borst B, Peters JB, Brink M, Schoon Y, Bleeker-Rovers CP, Schers $\mathrm{H}$, et al. Comprehensive health assessment three months after recovery from acute COVID-19. Clin Infect Dis. 2020. https://doi.org/10.1093/cid/ ciaa1750

99. Mattioli F, Stampatori C, Righetti F, Sala E, Tomasi C, De Palma G. Neurological and cognitive sequelae of Covid-19: a four month follow-up. J Neurol. 2021. https://doi.org/10.1007/s00415-021-10579-6.

100. Olezene CS, Hansen E, Steere HK, Giacino JT, Polich GR, Borg-Stein J, et al. Functional outcomes in the inpatient rehabilitation setting following severe COVID-19 infection. PLoS ONE. 2021;16(3):0248824. https:// doi.org/10.1371/journal.pone.0248824.

101. Kuo CL, Pilling LC, Atkins JL, Masoli JAH, Delgado J, Kuchel GA, et al. APOE e4 genotype predicts severe COVID-19 in the UK biobank community cohort. J Gerontol A. 2020;75(11):2231-2. https://doi.org/10. 1093/gerona/glaa131

102. Wen Y, Yang S, Liu R, Simpkins JW. Transient cerebral ischemia induces site-specific hyperphosphorylation of tau protein. Brain Res. 2004:1022(1-2):30-8, https://doi.org/10.1016/j.brainres.2004.05.106.

103. Cavalagli A, Peiti G, Conti C, Penati R, Vavassori F, Taveggia G. Cranial nerves impairment in post-acute oropharyngeal dysphagia after COVID-19. Eur J Phys Rehabil Med. 2020;56(6):853-7. https://doi.org/10. 23736/s1973-9087.20.06452-7.

104. Nersesjan V, Amiri M, Lebech AM, Roed C, Mens H, Russell L, et al. Central and peripheral nervous system complications of COVID-19: a prospective tertiary center cohort with 3-month follow-up. J Neurol. 2021. https://doi.org/10.1007/s00415-020-10380-X.

105. Huang C, Huang L, Wang Y, Li X, Ren L, Gu X, et al. 6-month consequences of COVID-19 in patients discharged from hospital: a cohort study. Lancet. 2021;397(10270):220-32. https://doi.org/10.1016/s01406736(20)32656-8

106. Connors JM, Levy JH. Thromboinflammation and the hypercoagulability of COVID-19. J Thromb Haemost. 2020;18(7):1559-61. https://doi. org/10.1111/jth.14849.

107. Akhtar N, Abid FB, Kamran S, Singh R, Imam Y, AlJerdi S, et al. Characteristics and comparison of 32 COVID-19 and non-COVID-19 ischemic strokes and historical stroke patients. J Stroke Cerebrovasc Dis. 2021;30(1):105435. https://doi.org/10.1016/j.jstrokecerebrovasdis.2020. 105435.

108. Wu Y, Chen F, Wang Z, Feng W, Liu Y, Wang Y, et al. Reductions in hospital admissions and delays in acute stroke care during the pandemic of COVID-19. Front Neurol. 2020;1 1: 584734. https://doi.org/10.3389/fneur. 2020.584734.

109. Leta V, Rodríguez-Violante M, Abundes A, Rukavina K, Teo JT, FalupPecurariu C, et al. Parkinson's disease and post-COVID-19 syndrome: the Parkinson's long-COVID spectrum. Mov Disord. 2021;36(6):1287-9. https://doi.org/10.1002/mds.28622.

110. Abu-Rumeileh S, Abdelhak A, Foschi M, Tumani H, Otto M. Guillain-Barré syndrome spectrum associated with COVID-19: an up-to-date systematic review of 73 cases. J Neurol. 2021;268(4):1133-70. https://doi.org/ 10.1007/s00415-020-10124-X.

111. Filosto M, Cotti Piccinelli S, Gazzina S, Foresti C, Frigeni B, Servalli MC, et al. Guillain-Barré syndrome and COVID-19: an observational multicentre study from two Italian hotspot regions. J Neurol Neurosurg Psychiatry. 2021;92(7):751-6. https://doi.org/10.1136/jnnp-2020-324837.

112. Zanin L, Saraceno G, Panciani PP, Renisi G, Signorini L, Migliorati K, et al. SARS-CoV-2 can induce brain and spine demyelinating lesions. Acta Neurochir (Wien). 2020;162(7):1491-4. https://doi.org/10.1007/ s00701-020-04374-x.

113. Leonhard SE, Mandarakas MR, Gondim FAA, Bateman K, Ferreira MLB, Cornblath DR, et al. Diagnosis and management of Guillain-Barré syndrome in ten steps. Nat Rev Neurol. 2019;15(11):671-83. https://doi. org/10.1038/s41582-019-0250-9.

\section{Publisher's Note}

Springer Nature remains neutral with regard to jurisdictional claims in published maps and institutional affiliations. 